\section{Youth of today is the future of tomorrow}

\author{
Justin Carrard, ${ }^{1,2}$ Boris Gojanovic ${ }^{3,4}$
}

\section{THE IMPORTANCE OF GRASSROOTS PROGRAMMES}

The future of Sports and Exercise Medicine (SEM), a young medical discipline, rests heavily on the involvement and commitment of the current generation of medical students. SEM is a fully recognised specialty on a handful of countries, something that is not mirrored in the majority of regions worldwide, ${ }^{1}$ and SEM will not form any meaningful part of the medical curriculum in universities in most countries. ${ }^{23}$ This exclusion from the academic process results in limited awareness among students and physicians about what SEM actually involves. SEM's role in the fight against the burden of noncommunicable diseases is simply ignored or misunderstood at best. ${ }^{4}$ If we, as SEM practitioners, are to stand a chance of harnessing the medical potential of SEM, we need to acknowledge the importance of grassroots development, that is, undergraduate programme.

Inspired by the British (Undergraduate Sports and Exercise Medicine Society, USEMS) and Australian models (Sports and Exercise Medicine Students' Association, SEMSA),${ }^{56}$ we decided to establish a new commission, called 'Student \& Junior Doctors SGSM/SSMS (Swiss Sports Medicine Society),' within our existing Swiss Sports Medicine Society. This commission includes students and junior resident doctors with an interest in sports medicine, physical activity and health, aims to promote SEM among undergraduate medical programme. It will use targeted social media strategies, alongside the traditional forms of communication (eg, conferences, newsletters, and so on). So

'Department for Internal Medicine, Centre Hospitalier de Bienne (BE), Meyrin, Switzerland

${ }^{2}$ University of Lausanne, Lausanne, Switzerland

${ }^{3}$ Hôpital de La Tour, Swiss Olympic Medical Center, Meyrin, Switzerland

${ }^{4}$ Department for Human Locomotion (DAL), Sports Medicine, Lausanne University and Hospital, Lausanne, Switzerland

Correspondence to Dr Boris Gojanovic, Swiss Olympic Medical Center, Hôpital de La Tour, Meyrin, 1217 Geneva, Switzerland; boris.gojanovic@latour.ch how did we set about this challenging project?

\section{BJSM BLOG}

The 'Swiss Junior Doctors and Undergraduate Perspective on Sports and Exercise Medicine Blog' is the active voice of our movement and the support of the BJSM was crucial to the launch of this initiative. All the medical students and junior doctors in Switzerland now have an opportunity to engage in the conversation and express their opinions, for the benefit of the international SEM community. In addition, it provides the students with an opportunity to read the scientific literature, gain academic experience and develop their networking skills as they interview and interact with the experts in Switzerland.

\section{ONLINE NATIONAL SURVEY}

Currently, only four of the five Swiss medical schools offer a limited facultative SEM course. Thus, only a minority of students can access the full range of SEM topics. We strongly believe that SEM teaching should be an integral part of the core medical curriculum in Switzerland. To better understand our students' expectation and motivation, we recently started an online national survey of all Swiss medical students. It appears that the vast majority of students (approximately 95\% as per our preliminary analysis) want to include SEM as part of the curriculum at universities, and once the survey is finalised, we will approach each of the Deans involved to discuss the potential for SEM education.

\section{STUDENTS DAY}

At the SGSM/SSMS Annual Meeting, taking place in Interlaken in the beautiful Bernese Alps from 25 to 27 October, we will hold our second Annual Students Day and we are delighted to welcome Stefan Griffin, USEMS copresident, as a guest speaker. His presence underlines our strong belief in the need for international collaboration at the undergraduate level. The purpose of the Students Day is to introduce students to classic SEM topics (concussion, sudden cardiac death, exercise is medicine and musculoskeletal examination), as well as develop networking and sharing of ideas.

\section{THE FUTURE: EMPOWERING AND EDUCATING YOUNG MEDICS}

In the years ahead, we will make a major effort to influence universities and include a substantial SEM curriculum at every Swiss medical school. In addition, we will strengthen our national commission, develop local SEM chapters at Swiss medical schools and improve our relationship with fellow societies like the USEMS and SEMSA. On the international stage, we hope that we can help our SEM colleagues to develop SEM as an established medical specialty and create postgraduate training positions for SEM students. In the 2016 Swiss edition of BJSM, SGSM/SSMS enthusiastically joined the BJSM member societies community. One year later, we are totally committed to contribute to SEM's development and future.

Twitter Justin @Carrard.Justin, Boris Gojanovic @ DrSportSante, @SwissSportsMed

Competing interests None declared.

Provenance and peer review Commissioned; internally peer reviewed.

(C) Article author(s) (or their employer(s) unless otherwise stated in the text of the article) 2017. All rights reserved. No commercial use is permitted unless otherwise expressly granted.



To cite Carrard J, Gojanovic B. Br J Sports Med 2017;51:1315.

Br J Sports Med 2017;51:1315.

doi:10.1136/bjsports-2017-098313

\section{REFERENCES}

1 Cullen M. Developing a new specialty - sport and exercise medicine in the UK. Open Access J Sports Med 2010;1:11-14

2 Cullen M, McNally O, Neill SO, et al. Sport and exercise medicine in undergraduate medical schools in the United Kingdom and Ireland. Br J Sports Med 2000;34:244-5.

3 Kordi R, Moghadam N, Rostami M. Sports and exercise medicine in undergraduate medical curricula in developing countries: a long path ahead. Med Educ Online 2011;16.

4 World Health Organisation. Noncommunicable diseases. http://www.who.int/mediacentre/factsheets/fs355/en/

5 Undergraduates-USEMS. Faculty of Sport and Exercise Medicine. http://www.fsem.ac.uk/training-education/ undergraduates-usems.aspx

6 Semsa. sports and exercise medicine students' association. http://www.semsa.org.au/ 